\title{
Lateral arm flap: indications and techniques
}

\author{
Zinon T. Kokkalis ${ }^{1} \cdot$ Efstratios Papanikos ${ }^{1} \cdot$ George A. Mazis $^{2} \cdot$ Andreas Panagopoulos $^{1} \cdot$ Petros Konofaos $^{3}$
}

Received: 22 February 2020 / Accepted: 27 February 2020 / Published online: 17 June 2020

(c) Springer-Verlag France SAS, part of Springer Nature 2020

Dear Sir,

We thank Dr. Fang for giving us the opportunity to clarify a few points in our article [1] that might be misunderstood.

As we mention in our article, the main blood supply of lateral arm flap (LAF) is the posterior radial collateral artery (PRCA) that gives most of the flaps septocutaneous branches. "The main branch of the RCA that supplies the lateral arm flap is the PRCA," and it is the branch that is used as the base of the flap. Later in the article in Harvesting technique, we describe a step that we ligate the ARCA branch. "The anterior branch of the radial collateral artery (ARCA) is ligated distally from the bifurcation of the RCA, and further dissection of the RCA is accomplished proximally up to its origin to the profunda brachii artery." However, Hennerbichler et al. [2] described some anatomic variations in $8 \%$ of the population ARCA also give a septocutaneous branch to the LAF. Furthermore, ARCA is in close proximity to the radial nerve as it accompanies it along its course between the brachialis and the brachioradialis muscles. Maybe it is not clear from the text and we did not emphasize enough that anatomic variations and close proximity to the radial nerve are not the main reasons but additional reasons as to why we cannot base the LAF of the ARCA.

The venous system of the LAF consists of two networks, the superficial and the deep. Between them at least two large anastomosing veins exist and clinically either the superficial or the deep venous network is enough to drain the flap [3]. In the anatomy paragraph of the article, we just briefly described the two systems and where each one drains. The

Zinon T. Kokkalis

drkokkalis@gmail.com

1 Department of Orthopaedics, School of Medicine, University Hospital of Patras, University of Patras, Papanikolaou 1, 26504 Rio, Patras, Greece

2 Private Practice, Athens, Greece

3 Department of Plastic Surgery, University of Tennessee Health Sciences Center, Memphis, TN, USA deep venous system drains into the profunda brachii veins and the superficial into the cephalic vain. However, as we described in the Harvesting technique, the deep venous system is used, as it forms the venae comitantes of the PRCA. "Once adequate pedicle length is gained, the PRCA and venae comitantes are divided and used as the pedicle of the lateral arm flap." Maybe a misunderstanding occurs because we did not clarify in the anatomy paragraph of the article as to why the deep venous system is the preferred one and its advantages over the use of the superficial one. Thank you for giving us the chance to clarify that the deep venous system with the venae comitantes of the PRCA is the preferred venous system for the LAF.

\section{Compliance with ethical standards}

Conflict of interest The authors declare that they have no conflict of interest.

\section{References}

1. Kokkalis ZT, Papanikos E, Mazis GA, Panagopoulos A, Konofaos P (2019) Lateral arm flap: indications and techniques. Eur J Orthop Surg Traumatol 29:279-284

2. Hennerbichler A, Etzer C, Gruber S, Brenner E, Papp C, Gaber O (2003) Lateral arm flap: analysis of its anatomy and modification using a vascularized fragment of the distal humerus. Clin Anat 16:204-214

3. Rivet D, Buffet M, Martin D, Waterhouse N, Kleiman L, Delonca DBJ (1987) The lateral arm flap: an anatomic study. J Reconstr Microsurg 3:121-132

Publisher's Note Springer Nature remains neutral with regard to jurisdictional claims in published maps and institutional affiliations. 